First publ. in: Physica Status Solidi / B, Vol. 174 (1992), 1, pp. 295-300

Fakultäl für Physik, Universität Konstanz ${ }^{1}$ )

\title{
Optical Reflectivity of Si above the Melting Point
}

\author{
By \\ J. Boneberg, O. Yavas, B. Micrswa, and P. Leiderer
}

The variation of the optical reffectivity of a Si single crystal during irradiation with two successive Nd:YAG laser pulses is investigated with ns resolution. The first pulse melts the surface and therefore the reflection coefficient increases up to the value of the metallic liquid at the melting temperature $(1685 \mathrm{~K})$. Upon further heating the surface with the second, time-delayed pulse, a decrease of the reflection coefficient is observed, resulting from the temperature-dependent dielectric function of the molten Si. The largest decrease in the reflectivity that could be reached before damaging the surface amounted to $9 \%$ for a probe wavelength of $633 \mathrm{~nm}$. The application of a simple Drude model for the optical constants above the melting point is discussed.

Die Änderungen im optischen Reflexionsvermögen eines Silizium-Einkristalles während der Bestrahlung mit zwei aufeinander folgenden Nd:YAG-Laserpulsen wird mit ns Auflösung untersucht. Der erste Puls schmilzt die Oberfläche, und der Reflexionskoeffizient steigt daher auf den Wert der metallischen Flüssigkeit am Schmelzpunkt $(1685 \mathrm{~K})$. Weiteres Heizen der Oberfläche mit dem zweiten, zeitverzögerten Puls führt zu einer Verringerung des Reflexionsvermögens aufgrund der temperaturabhängigen dielektrischen Funktion des geschmolzenen Si. Die größte Verringerung des Reflexionsvermögens, die erreicht werden kann, bevor die Oberfläche zerstört wird, beträgt $9 \%$ für eine Téstwellenlänge von $633 \mathrm{~nm}$. Die Anwendung eines einfachen Drudemodells für die optischen Konstanten über dem Schmeizpunkt wird diskutiert.

\section{Introduction}

The thermal model for nanosecond laser annealing of $\mathrm{Si}$ is widely accepted. Above a certain (pulse-width and wavelength dependent) energy threshold $E_{\mathrm{t}}$ the surface of a silicon crystal is melted [1]. The recrystallisation of the melt proceeds from the crystal-liquid boundary and moves towards the surface on a nanosecond timescale. A series of time-resolved experiments (LEED [2], X-rays [3], and optical measurements [4]) as well as the numerical solution of the heat diffusion equation [5] support this model in the low-energy range. Experiments in the higher-energy range $\left(E>2 E_{\imath}\right)$ show that the temperature of the liquid surface can considerably exceed the melting temperature $\left(T_{\mathrm{m}}=1685 \mathrm{~K}\right)$. Time-of-flight measurements of atoms evaporated from the surface by a nanosecond laser pulse indicate a temperature between 2000 and $3000 \mathrm{~K}$ [6]. Time-resolved pyrometric measurements of the surface temperature show temperatures above $2000 \mathrm{~K}$ as well [7]. A consequence of the increasing temperature of the melt should be a change in the optical constants of the liquid and in particular a change of the reflection coefficient. Although there are some indications that a variation of the optical constants does indeed exist [4], the only systematic investigation of the optical properties in the high-energy regime found no change [8].

In this work we report on a detailed study showing a distinct decrease of the reflection coefficient of $\mathrm{Si}$ in the liquid phase heated well above the melting temperature during ns laser annealing.

1) Postfach 5560, W-7750 Konstanz, FRG.

Konstanzer Online-Publikations-System (KOPS)

URL: http://www.ub.uni-konstanz.de/kops/volltexte/2007/3089/

URN: http://nbn-resolving.de/urn:nbn:de:bsz:352-opus-30897 


\section{Experimental}

The samples used here were polished silicon wafers with (100) and (111) orientation. The annealing laser was a frequency-doubled Q-switched $\mathrm{Nd}$ : Y AG with a pulse length of $7 \mathrm{~ns}$ (FWHM) and a beam profile close to $\mathrm{TEM}_{00}$. For the measurements of the reflectivity we used a focused, p-polarized HeNe laser beam $(\lambda=633 \mathrm{~nm}, 7 \mathrm{~mW})$ with an angle of incidence of $30^{\circ}$ and a $1 /$ e diameter at the sample surface of $20 \mu \mathrm{m}$. The $\mathrm{Nd}$ :YAG laser pulse, incident perpendicular to the surface, was only mildly focused to a spot diameter of about $0.5 \mathrm{~mm}$, i.e. the variation of the pulse laser beam across the diameter of the test laser focus was small. The light reflected from the surface was detected by a pin diode (risetime $<1$ ns) and registered by a fast digital storage oscilloscope (HP 54111D). Interference filters in front of the pin diode suppressed contributions of the $\mathrm{Nd}: \mathrm{YAG}$ light to the measured signal. For the double pulse experiments the Nd:YAG laser beam was split by a $50: 50$ beam splitter, one part being delayed with respect to the other by $28 \mathrm{~ns}$ and then focused onto the same spot of the sample.

\section{Results and Discussion}

In principle, information about the laser-induced change of the surface temperature and reflectivity in the liquid state can be obtained from single pulse experiments. However, the double pulse measurements described here are interpreted more readily: The leading pulse generates a molten layer thick compared to the penetration depth of the laser light, so that the second pulse - which is the one to be analysed in detail - is absorbed under well-defined conditions. Moreover, the effects due to heating the liquid surface are relatively subtle and thus in a single pulse experiment are easily obscured by the huge change in the reflectivity upon melting. By contrast, in a double pulse experiment these two processes are well separated.

In the examples given below the energy density of the first pulse was held fixed at $E_{1}=1.0 \mathrm{~J} / \mathrm{cm}^{2}$, whereas the energy density of the second delayed pulse was varied. In Fig. 1 a to d four reflectivity curves are plotted for $E_{2}=0,0.5,1.4$, and $1.8 \mathrm{~J} / \mathrm{cm}^{2}$, respectively. Fig. 1a, which represents the effect of laser heating by the first pulse alone, shows that at the given energy density a molten layer is created which exists for $55 \mathrm{~ns}$, in good agrecment with previous work [4]. In the trace of Fig. $1 \mathrm{~b}$, the reflectivity appears not to be affected within the experimental resolution as the delayed pulse (whose position is marked by an arrow) hits the surface. Nevertheless, the additional energy input due to the second pulse manifests itself in an increased lifetime of the high reflectivity liquid phase, $125 \mathrm{~ns}$ in this case. As the energy of the second pulse is further increased, however, the heating of the liquid surface leads to a clearly discernible dip in the reflectivity (e.g. $\Delta R=3.4 \%$ at $E_{2}=1.4 \mathrm{~J} / \mathrm{cm}^{2}$ in Fig. $1 \mathrm{c}$ ). This dip becomes even more pronounced at higher energies, reaching $\Delta R=9 \%$ at $E_{2}=1.8 \mathrm{~J} / \mathrm{cm}^{2}$ (Fig. $1 \mathrm{~d}$ ). Beyond that value the surface is permanently damaged. The energy dependence of this effect is shown in more detail in Fig. 2, where data for the value of the reflectivity minimum in the dip are plotted versus the pulse energy density $E_{2}$.

A closer inspection of the data of Fig. 1 reveals that the minimum reflectivity in the dip is reached slightly after the intensity maximum of the second laser pulse. Afterwards $R$ relaxes back to the rellectivity of the liquid $\mathrm{Si}$ at the melting temperature with a time constant of $10 \mathrm{~ns}$. 


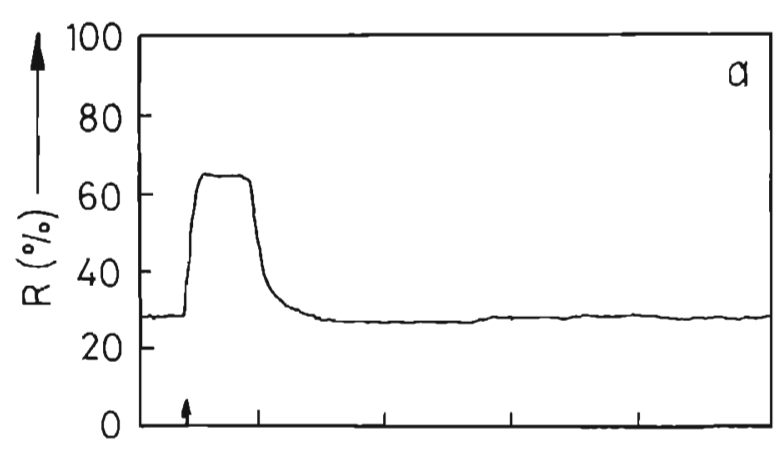

Fig. 1. Time-resolved reflectivity trace $E_{2}=1.0 \mathrm{~J} / \mathrm{cm}^{2}$. a) $E_{2}=0$, b) 0.5 , c) 1.4, d) $1.8 \mathrm{~J} / \mathrm{cm}^{2}$. Laser pulses are marked by arrows
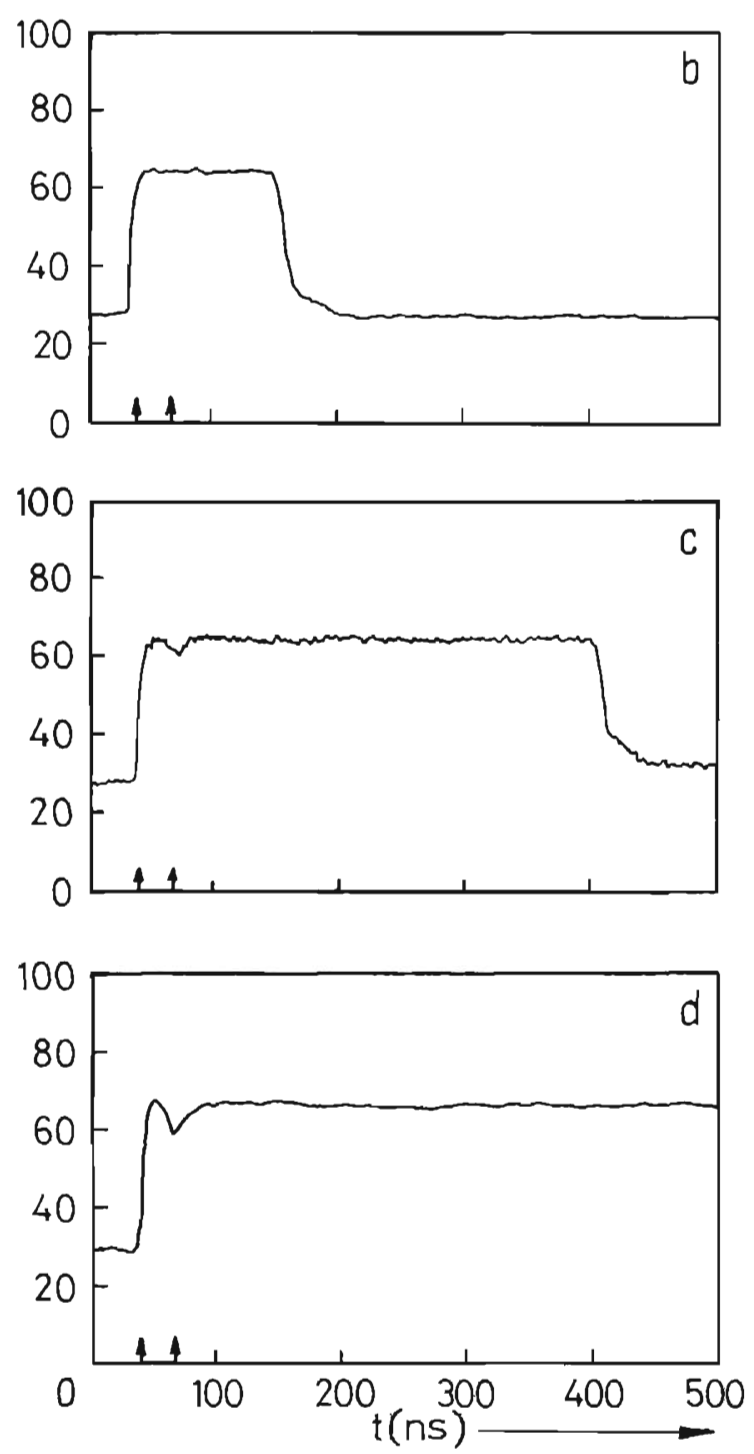

We observed no measurable difference in the behaviour of the Si(100) and the $\operatorname{Si}(111)$ surface. Simultaneous measurements of the reflectivity at $488 \mathrm{~nm}$ show essentially the same results [9].

In order to describe the behaviour of the optical constants with increasing temperature we use a Drude model, following Gusakov et al. [8]. The dielectric function $\varepsilon=\varepsilon_{1}+i \varepsilon_{2}$ can be written in the form

$$
\begin{aligned}
\varepsilon(\omega)=1 & -\frac{\omega_{\mathrm{p}}^{2}}{\omega^{2}+\omega_{\mathrm{c}}^{2}} \\
& -i \frac{\omega_{\mathrm{p}}^{2}}{\omega^{2}+\omega_{\mathrm{c}}^{2}} \frac{\omega_{\mathrm{c}}}{\omega},
\end{aligned}
$$

where $\omega_{c}$ is the plasma frequency of the electrons and $\omega_{\mathrm{c}}$ the electron-phonon collision frequency. In a first approximation we consider $\omega_{\mathrm{p}}$ to be constant in the melt at all temperatures and assume the collision frequency to increase linearly with temperature [8],

$\omega_{c}(T)=\omega_{c}\left(T_{\mathrm{m}}\right) \frac{T}{T_{\mathrm{m}}}$.

$\omega_{\mathrm{c}}\left(T_{\mathrm{n}}\right)$ is taken from the optical constants of liquid silicon at the melting point [10]. On the basis 


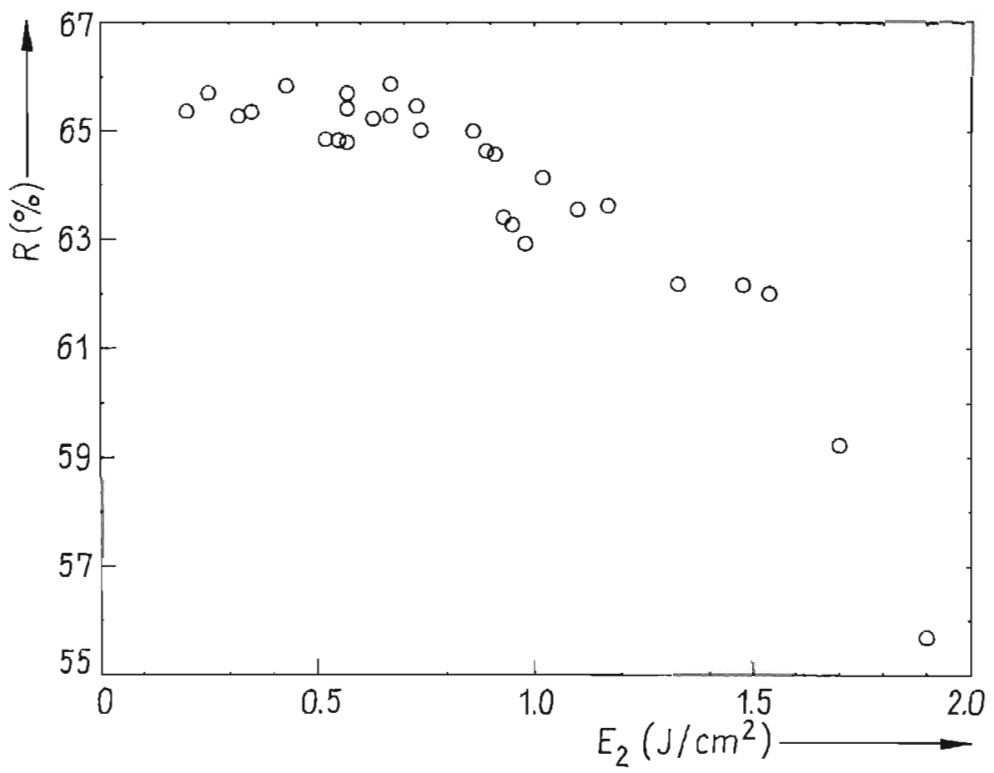

Fig. 2. Minimum value of the reflectivity dip resulting from the second pulse with cncrgy $E_{2}$

of (1) and (2) one obtains a temperature-dependent reflectivity (Fig. 3, curve 1), which can be used to derive the surface temperature of the molten Si from the measured values of the reflection coefficient. The resulting surface temperatures corresponding to the reflectivity data of Fig. 2 are shown as squares in Fig. 4.

On the other hand, we have calculated the surface temperature as a function of the laser pulse energy by solving the heat diffusion equation (based on the finite difference method [5]). In the calculation the change of the optical constants of the liquid resulting from (1) and (2) were taken into account. The surface temperatures obtained in this way were distinctly higher than those resulting from the measurements (see Fig. 4). Regarding the time dependence, however, the calculations show the same relaxation behaviour as the measured signal: the reflectivity decrease disappears with a time constant of $10 \mathrm{~ns}$.

The discrepancy displayed in Fig. 4 indicates that the simple Drude model used above is not sufficient to describe the reflectivity reduction of the melt. In a more extended approach we have therefore taken into account two additional effects which influence $R(T)$ : (i) the thermal expansion [13] and (ii) the destruction of persistent covalent bonds in the liquid [14]. Good agreement between the measured and calculated data is obtained if we assume that $\omega_{\mathrm{p}}$ increases with temperature as $\omega_{\mathrm{p}}^{-1}\left(\mathrm{~d} \omega_{\mathrm{p}} / \mathrm{d} T\right)=2 \times 10^{-4} \mathrm{~K}^{-1}$, due to the second contribution (the first contribution only yields a small correction of opposite sign). The resulting $R(T)$ is shown in Fig. 3 (curve 2). A detailed discussion of these models will be the topic of a separate paper.

The measured surface temperatures as well as the reduced reflection coefficients are consistent with experimental data of other groups: As remarked in the Introduction the experiments of Stritzker et al. [6] and Kemmler et al. [7] indicate temperatures above $2000 \mathrm{~K}$. In the work of Baeri et al. [11] and Surko et al. [12] a reflection coefficient several percent smaller than the value at the melting point was used to get agreement between calculations 


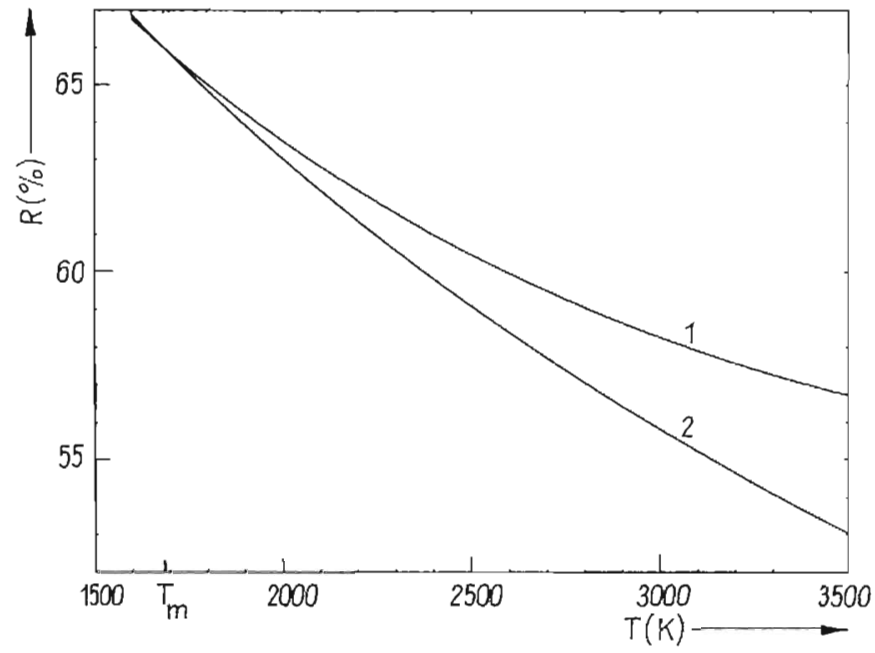

Fig. 3. Temperature dependence of the reflectivity using (1) the simple Drude model, (2) the extended model as discussed in the text

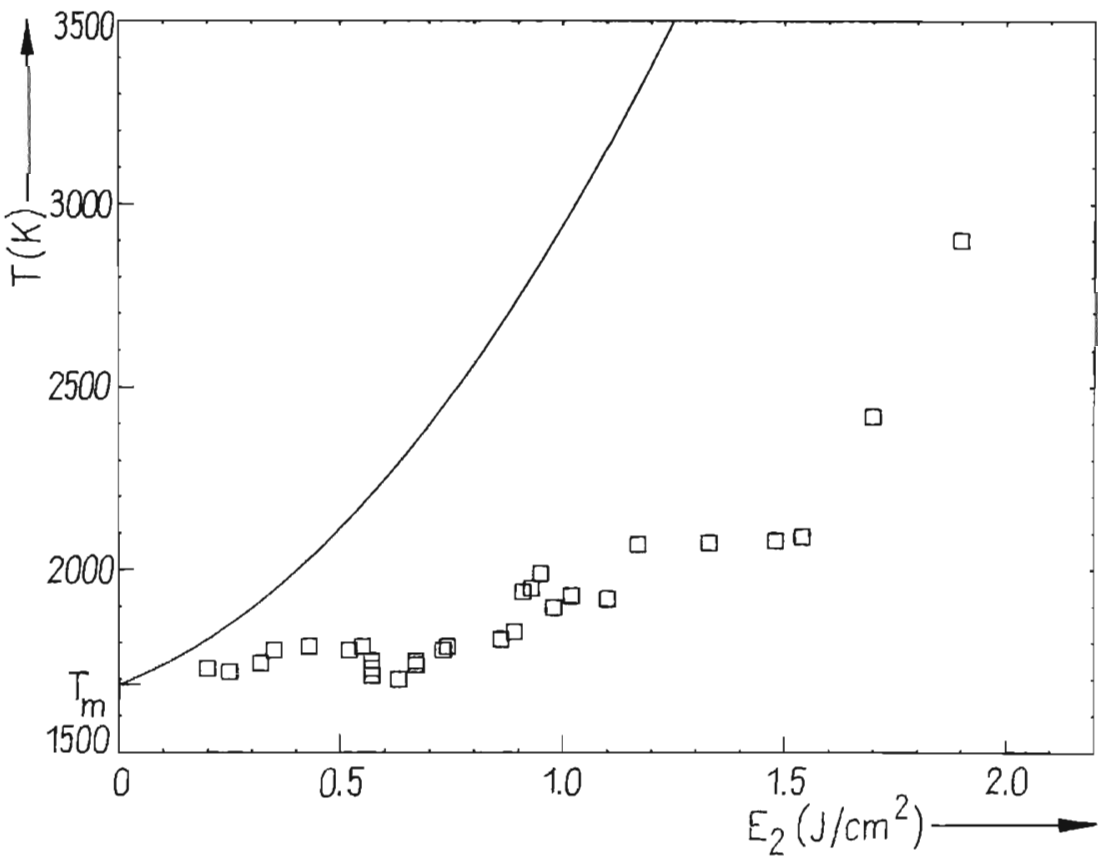

Fig. 4. Maximum surface temperature resulting from the second pulse with energy $E_{2}$ as calculated from heat diffusion equation (solid line) and from the experimental data of Fig. 2 using the Drude model (squares) 
and the experimental results. This can be explained on the basis of the temperature-dependent dielectric function.

The question remains why Gusakov et al. [8] did not find any temperature-related changes of the dielectric constants in their experiment, which was quite similar to our arrangement except for the different timescale (their laser pulses are ten times longer). They suggest that on their timescale on additional mechanism for heat conduction (convection) may be involved.

In summary our measurements complete the thermal model of nanosecond laser annealing. The experiments show that the optical constants of the liquid Si change with temperature. The reduction in reflectivity during the laser pulse, which may increase the absorbed energy up to $30 \%$, has to be considered in numerical calculations of laser annealing and results in higher surface temperatures and longer melting times compared to calculations where the reflectivity change is neglected.

\section{Acknowledgements}

We would like to thank S. Herminghaus for many useful discussions. This work was supported by Zentrum II für Energieforschung at the University Konstanz (J. B.) and by the Friedrich-Ebert-Stiftung Bonn (O. Y.).

\section{References}

[1] J. M. Poate, Laser Annealing of Semiconductors, Academic Press, New York 1982.

[2] R. S. BeckliR, G. S. Higashi, and J. A. Gorovchenko, Phys. Rev. Letters 52, 307 (1984).

[3] B. C. Larson, C. W. White, and T. S. Noggr.e, Phys. Rev. Letters 48, 337 (1982).

[4] D. H. Austov, J. A. Golovchenko, A. L. Simons, R. E. Slusher, P. R. Smith, C. M. Surko, and T. N. C. Venkatesan, Dynamics of Laser Annealing, Laser Solid Interactions and Laser Processing, AIP, New York 1979.

[5] P. Balki, S. U. Campisano, G. Foti, and E. Rimini, Appl. Phys. 50, 788 (I979).

[6] B. Stritzker, A. Posolezczyk, and J. A. Tagle, Phys. Rev. Letters 47, 356 (1981).

[7] M. Kemmler, G. WartManN, and D. von der Linde, Appl. Phys. Letters 45, 159 (1984).

[8] G. M. GuSAKOv, A. A. KOMARNitskiI, and A. S. EM, phys. stat. sol. (a) 107, 261 (1988).

[9] J. Boneberg, O. Yavas, B. Mrerswa, and P. Leiderer, Proc. SPIE 1598, 84 (1991).

[10] G.E. Jellison, Ir. and D. H. Lowndes, Appl. Phys. Letters 51, 352 (1987).

[11] P. Baeri, S. U. Campisano, G. Foti, and E. Rimini, Appl. Phys. Letters 33, 137 (1978).

[12] C. M. Surko, A. L. Simons, D. H. Alston, J. A. Golovchenko, R. E. Slusher, and T. N. VenKATESAN, Appl. Phys. Letters 34, 635 (1979).

[13] V. M. Gr.azov, Liquid Semiconductors, Plenum Press, New York 1969.

[14] I. Stich, R. Car, and M. Parrinello, Phys. Rev. B 44, 4262 (1991).

(Received May 13, 1992) 